\title{
Хлопов О.А. \\ Политика администрации Д.Трампа в отношении Африки
}

ФБГОУ ВО «Российский государственный гуманитарный университет» (Россия, Москва)

doi: 10.18411/lj-02-2021-271

idsp: ljournal-02-2021-271

\section{Аннотация}

Статья раскрывает причины формирования и изменения политики США в отношении стран Африки в период деятельности резидента Д. Трампа. Автор анализирует особенности и раскрывает направления политики США на африканском континенте: экономическое сотрудничеств, программы помощи в сфере укрепления социально-политической стабильности военной безопасности и борьбы с терроризмом. При новой администрации Дж. Байдена США вынуждены будут считаться с изменениями происходящими в Африке и пересмотреть ряд принципов избирательной вовлеченности со африканскими странами.

Ключевые слова: колониальная экспансия, региональная безопасность, финансовая помощь, терроризм, Африка, США.

\section{Abstract}

The article reveals the reasons for the formation and change of the US policy towards African countries during the period of the activity of the President D. Trump. The author analyzes the features and reveals the directions of US policy towards the African continent: economic cooperation, assistance programs in the field of strengthening the socio-political stability of military security and the fight against terrorism. Under the new administration of J. Biden, the United States will have to reckon with the changes taking place in Africa and revise a number of principles of selective engagement with African countries.

Key words: colonial expansion, regional security, financial assistance, terrorism, Africa, USA.

В ходе своей истории у Соединенных Штатов не было своих колоний в Африке. Это стало важным фактором в развитии отношений между США и африканскими странами после Второй мировой войны. В XIX веке между 1800 и 1885 гг. произошло массовое движение в Африку со стороны западноевропейских держав: Франции, Великобритании, Германии, Португалии, Бельгии, Испании. Это так называемая схватка за Африку привела к созданию пятидесяти четырех колониальных зависимых политических образований. В свою очередь в XX веке было только две независимые африканские нации: Эфиопия и Либерия. Примерно 90\% африканского континента было колонизировано.

Что поражает в этом аспекте африканской истории, так это отсутствие в то время там Соединенных Штатов. В первые годы XIX века у Соединенных Штатов был морской флот. Многие его порты на восточном побережье вели значительную торговлю с Западной Африкой, включая торговлю рабами и китобойный промысел. Во время президентства Томаса Джефферсона США выиграли берберийские войны против Северной Африки против пиратов, базировавшихся в Тунисе, Алжире и Ливии, которые занимались нападениями на коммерческое судоходство и прибрежные европейские сообщества на протяжении более века.

Отсутствие американских колоний в Африке не помешало американским компаниям от ведения торговли с Африкой. Торговля США с Африкой была достаточно важна, что привело к открытию правительство США консульства и коммерческих агентств по всему континенту - в Порт-Луи (Маврикий) в 1794 г., в 
Кейптауне (Южная Африка) в 1799 г., в Батерсте (Гамбия) в 1834 г. и Луанда (Ангола) в 1850 г., а к 1862 г. в Африке было двадцать пять консулов и торговых агентов США. Американские компании были заинтересованы в основном в импорте слоновой кости, пальмового масла и кожи [1].

ВМС США также активно патрулировали Атлантический океан вдоль африканского побережья. В Соглашении Вебстера-Эшбертона 1842 г. между Соединенными Штатами Штаты и Великобританией, США согласились сотрудничать в подавлении работорговли, несмотря на то, что рабство оставалось законным в Соединенных Штатах. Это обязательство требовало от США поддерживать должным образом активное военно-морское патрулирование вдоль африканского побережья. К концу XIX века Соединенные Штаты боролись с Испанией, и в результате военных действий это привело к приобретению испанских территорий, которые стали колониями США, в частности, Филиппинские острова и Гуам в западной части Тихого океана и Пуэрто-Рико в Карибском море [2].

Идеологический поворот США против колониализма начался с президента Вудро Вильсона в 1918 г. В апреле 1917 г. Соединенные Штаты вступили в Первую мировую войну против Германии на стороне Франции и Англии, поскольку Уилсон был переизбран в 1916 г. под лозунгом «Он не дал нам войны», ему нужно было разработать идеологическое обоснование принятия Соединенные Штаты в войну. Это приняло форму его знаменитых «Четырнадцать пунктов», в которых была представлена повестка дня на послевоенное будущего устройства мира, в котором все споры будут разрешаться мирно и прозрачно, на основе демократии служащей необходимым объединяющим элементом. В этом документе президент Вильсон также обратился к колониализму. Его пятый пункт призывал к «беспристрастной корректировке всех колониальных требований, при строгом соблюдении принципа, согласно которому интересы населения должны иметь равный вес со справедливыми требованиями правительств, название которых будет определено». Он также призвал к предоставлению автономии европейским территориям, находившихся под властью Турции и Австро-Венгерской империи. Он не упомянул об африканских территориях, но основной смысл автономий для колониальных народов был ясен [3].

«Четырнадцать пунктов» Вудро Вильсона намного опередили свое время. В то время как вклад США в военные действия против Германии имел решающее значение для победы союзников, формула Вильсона послевоенного мира, гармонии и демократия полностью игнорировалась в мирных договоренностях. Одно из самых ранних проявлений вильсонианских взгляда американского президента Фраклина Рузвельта на колониализм проявился в августе 1941 г., когда англичане воевали против Германия и Японии, в то время как США оставались еще официально нейтральными. Рузвельт встретился с премьер-министром Великобритании Уинстоном Черчиллем в США на военном корабле у берегов Ньюфаундленда, чтобы обсудить, как государства могут быть полезны в военных усилиях Великобритании, фактически не вторгаясь в войну. В дополнение к соглашениям о предоставлении во временное пользование американской военной техники, два государственных деятеля подписали документ, который стал известен как «Атлантическая хартия», заявление об их совместном видении послевоенных целей.

Среди восьми абзацев хартии третий явно был в трактовке вильсонианства: «Они уважают право всех народов выбирать форму правительства, при котором они будут жить, и они хотят видеть суверенное права и восстановления самоуправления для тех, кто был насильственно лишены их» [4].

Все колониальные державы участвовали в деколонизации в 1950-х гг., начиная с Ливии в 1951 г., Судана, Марокко и Туниса в 1956 г и Ганы в 1957 г. В 1958 г. Государственный департамент при президентстве Д. Эйзенхауэра создал Бюро по африканским делам под руководством помощника государственного секретаря по 
африканским делам, для развития отношений со странами Африки к югу от Сахары. Страны Северной Африки находились в ведении Бюро по делам Ближнего Востока. Администрация Кеннеди также создала Корпус мира, который отправил тысячи молодых американских добровольцев для службы в местных деревнях. Агентство США по международному развитию (USAID) начало оказывать денежную экономическую помощь, а Пентагон предоставил средства и боеприпасы для местных армий. Эйфория закончилась, когда конголезский кризис 1960-х гг. показал очень крупномасштабную нестабильность.

В ходы «холодной войны» африканский континент стал ареной жесткой идеологической борьбы и военно-политического противостояния между США и СССР. Существенные изменения произошли после распада СССР и биполярной системы мира,

После периода политической и социальной нестабильности, а также слабого экономического роста в 1990-2000-х гг. положение Африки начало меняться. С тех пор экономическая политика и деловая среда на континенте по большей части значительно улучшились. Появление информационных и телекоммуникационных технологий способствует экономической и социальной интеграции, а также развитию инноваций и предпринимательской деятельности по всему континенту. Эти факторы, наряду с благоприятной внешней средой, в частности списанием долгов и более высокими ценами на сырьевые товары, способствовали устойчивому экономическому росту за последние два десятилетия. Кроме того, средний класс расширяется и увеличивает расходы потребителей и бизнеса почти на 4 \% в год [5].

Когда Дональд Трамп вступил в должность Президента США в январе 2017 г., он имел список международных договоров и нескольких многосторонних экономических соглашений, заключенных несколькими из его предшественников, которые, по его мнению, противоречат интересам США. К ним относятся соглашение об ограничении ядерных вооружений с Ираном - Совместный план комплексных действий (СВПД); Транстихоокеанское торговое партнерство (ТТП); Парижское соглашение об изменении климата; и Североамериканское соглашение о свободной торговле (НАФТА). Он объявил о выходе Соединенных Штатов из СВПД, ТТП и Парижское соглашение и потребовали пересмотра соглашения по НАФТА [6].

По мнению президента Д.Трампа, ряд международных торговые соглашения были несправедливы по отношению к американским рабочим, потому что они позволили продавать иностранные продукты в Соединенных Штатах по значительной более низкие цены, чем на те же товары, произведенные в Соединенные Штаты [7]. Поэтому было несколько удивительно, что президент Д.Трамп и его команда не сосредотачивалась на Законе о росте и возможностях Африки, подписанный президентом Клинтоном в 2000 г. Этот закон не подлежать пересмотру до 2025 г. и предусматривает что практически вся продукция, производимая в странах Африки к югу от Сахары, может поступать в США беспошлинно. Закон дает африканским странам большое преимущество по сравнению с другими странами-экспортерами. В результате некоторые инвесторы, которые, уже экспортируя в США из своих стран, открыли новые производственные мощности в Африке.

Единственный комментарий представителя администрации Трампа в 2018 г. поступил от министра торговли У.Росса, который выразил заинтересованность в заключении полного двустороннего соглашения о свободной торговле с одной африканской страной путем соблюдения принципа взаимности [8]. В течение первых двух лет администрации Трампа, 2017-2018 гг., политика США в отношении Африки была политикой преемственности. Основные программы начатые в президентство Б. Клинтона, Дж.Буша-мл и Б. Обамы остались на месте и были полностью профинансированы. Первоначальная концентрация администрации по антикризисному управлению 
В июне 2018 г. встречаясь с африканскими лидерами в Нью-Йорке, президент Д. Трамп попросил постоянного представителя США при ООН посла Никки Хейли поехать в Южный Судан и Демократическую Республику Конго (ДРК), чтобы определить, чем Соединенные Штаты могут помочь в прекращении насилие и нестабильность в этих странах.

В Южном Судане, где гражданский конфликт казался совершенно неразрешимым после пяти лет обретения независимости, посол Хейли рекомендовал США продолжают поддерживать африканское региональное посредничество. В ДРК, однако, Хейли решил, что Соединенные Штаты могут сыграть значительную прямую роль

К середине 2017 г., внутриполитическая ситуация в ДРК стала достаточно напряженной. Для решения этой конкретной проблемы посол Хейли отправился в ДРК в июне 2018 г. Ее визит привел к демократическому исходу [9]. После встречи с президентом Кабилой Хейли сообщил, что Кабила обещал провести президентские выборы не позднее декабря 2018 г. и взял на себя обязательство не участвовать в выборах. В 2019 г. ДРК завершились президентские выборы, и новый президент Феликс Чисекеди был приведен к присяге, чтобы заменить Джозефа Кабилу. Особое значение имеет тот факт, что эти выборы стали первой мирной передачей власти в Конго с момента обретения ею независимости от Бельгии в 1960 г.

Политика Трампа в отношении Африки начала провялятся с декабря 2018 г. Джон Болтон стал советником по национальной безопасности в апреле 2018 г. Его основная мысль заключалась в том, что процветание Африки будет хорошо для Соединенных Штатов во многих отношениях: экспортные рынки США будут расширены, и потребность в экономической помощи США будет уменьшено. Следовательно, официальная политика правительства США сделала упор на поддержку инвестиций со стороны частного сектора США.

Дж.Болтон охарактеризовал вмешательство КНР в Африку как «хищническое, направленное на контроль над природными ресурсами континента посредством предложения займов, которые, возможно, никогда не будут выплачены», и заявил, что частный сектор США будет эффективно конкурировать с Китаем. Он дал название программе администрации Трампа для поощрения частных инвестиций: «Процветающая Африка» (Prosper Africa). Болтон также обратился с торжественным посланием к африканцам, выразив идею о том, что США будут делать все, что в их собственных интересах: помощи не будет в страны, где коррупция отвлекает собственные ресурсы наций на частные банковские счета. В дополнение Соединенные Штаты начнут вести счет относительно того, насколько африканские правительства поддерживают политику США. Это будет особенно важно в ООН, где африканские делегации часто голосуют против Соединенных Штатов. Чаще всего это происходит во время голосования по израильско-палестинским вопросам.

В программе «Процветающая Африка» акцент был сделан на консультирование африканских правительства по созданию благоприятной среды для частного сектора, особенно в отношении верховенства закона, исполнения контрактов, обслуживания жизненно важных инженерных сетей и надлежащее управление портами и транспорт.

Помощником государственного секретаря США по Африке Президент Трамп выбрал посла Тибора Надя в 2018 г. В своих заявлениях о государственной политике Надь повторил слова Джона Болтона о повышении благосостояния Африки за счет инвестиций и торговли. Кроме того, он обратил внимание на «рост молодежи» в Африке, где 40\% населения Африки моложе двадцати пяти лет. Надь выступил за поощрение расширения возможностей получения образования и трудоустройства для этих молодых людей как важный двигатель экономического роста. При этом Надь сыграл важную роль в консолидации переход к демократии в Конго и передача власти в Судане от военного к гражданскому в первой половине 2019 г. [10]. 
Министерство иностранных дел администрации Трампа пыталось сократить помощь странам Африка. Риторика администрации Трампа в поддержку процветания Африки не соответствовали его бюджетным запросам, которые требовали значительного сокращения иностранной помощи. Конгресс принял закон об учреждении нового агентства, Международного агентства США Корпорация финансирования развития (USIDFC), известная как «Закон о строительстве», в котором говорится: «Этот закон устанавливает Международную корпорация финансирования развития для содействия участию капитала и навыков частного сектора в экономическом развитии странами с низким или ниже средним уровнем дохода и странами, переходящими от нерыночной к рыночной экономике, чтобы дополнить США помощь и цели внешней политики» [11].

C 1 октября 2019 г. USIDFC заменила «Корпорацию зарубежных частных инвестиций» (OPIC), которая предоставляла гарантии частному сектору от политических рисков за рубежом, а также финансирование приоритетных секторов, таких как энергетика. При первоначальном бюджете в \$60 млрд. USIDFC, основная часть усилия нового агентства будут направлены на Африку.

Борьба с терроризмом в Африке. В то время как Исламское государство (запрещенное в России) и его различные террористические группы отступали на Ближнем Востоке, в 2018-2019 гг. они расширяли свои операции в Сахельском регионе Африки. Сахель - это пояс с запада на восток страны непосредственно к югу от пустыни Сахара. Он простирается от Сенегала и Мавритании на Атлантическом океане на западе до Судана и Сомали на берегу Красного моря на востоке. Опираясь на местные вооруженные исламские группировки, влияние радикальных исламистов начало расти в Сахеле после падения ливийского лидера Муаммара Каддафи в 2011 г. Южная Ливия, охваченная анархией, стала крупным источником оружия для исламских боевиков. Помимо терроризма, эти вооруженные группы занимаются торговлей наркотиками, похищениями людей с целью получения выкупа, контрабандой золота и торговлей людьми.

Администрация Б. Обамы направила военных советников США в Нигер и организовал строительство базы дронов в Нигерии, в городе Агадес. Кроме того, при администрации Обамы Африканское командование США создало полноценную военную базу в Джибути на стратегическом проливе. Баб-эль-Мандеба, между Красным морем и Индийским океаном. Целью развертывания вооруженных сил США в регионе Сахеля была и остается - помощь африканским правительствам бороться с исламскими террористическими формированиями. Все развертывания носят рекомендательный характер, кроме Джибути, где военные подразделения США проводят целенаправленные действия против исламских группировок. В Джибути большинство действий связано с операциями «воздух-земля» [12].

Администрация Трампа унаследовала и продолжила это развертывание с некоторым сокращением персонала в соответствии с решимостью президента сократить военное присутствие США за рубежом. Основная проблема для администрации в регионе Сахеля - растущая неспособность африканских правительств справиться с террористическими атаками.

Дополнительная проблема для местных режимов является присоединение безработной молодежи к исламским ополченцам. Администрация Д. Трампа продолжала полагаться на местные африканские правительствам для борьбы с исламистской угрозой и предоставлять консультационную и логистическую поддержку.

C началом новой программы «Prosper Africa» президент Д.Трамп выразил намерение добавить к общим усилиям США, чтобы помочь Африке догнать ЮгоВосточную Азию и Латинскую Америку. в сокращении бедности [13]. 
Соединенные Штаты использовали различные подходы и инструменты для ответа на вооруженные действия исламистов в Сахеле, включая полномочия и средства, предоставленные Конгрессом. Дипломатическое взаимодействие и публичная дипломатия также являются частью инструментария США в регионе. США оказывают помощь африканским странам в области безопасности Сахеля, включая военную помощь, помощь в безопасности границ и создания полиции

Региональная программа по борьбе с терроризмом осуществляется в рамках программы «Транссахарское контртеррористическое партнерство» (Trans Sahara Counter Terrorism Partnership) (TSCTP), которая также включает некоторую помощь в развитии, наряду с обучением, проводимым Министерством обороны США и предоставление оборудования.

Государственный департамент предоставляет дополнительную помощь в области безопасности странам региона в рамках других региональных инициатив, включая Фонд партнерства по борьбе с терроризмом и Африканское региональное противодействие. Нигер, по всей видимости, является самым крупным получателем помощи США для контртеррористической деятельности, обучение и снаряжения в Сахеле за последнее десятилетие, за которым следуют Мавритания и Чад; финансирование для Буркина-Фасо также выросла в результате обострения кризиса безопасности в этой стране. Военная помощь Мали по-прежнему ограничивается правами человека и другими политическими проблемами, но страна получила значительную финансовую помощь за последние годы на обеспечении гражданской безопасности.

Помощь США в борьбе с терроризмом предоставляется странам Сахеля в соответствии с несколькими установленными законами и программами, в том числе программа Министерства обороны США «Глобальное обучение и оснащение», программа Операций по поддержанию мира (PKO) Государственного департамента. Военные США не наносят никаких прямых ударов по целям террористов в Сахель, в отличие от Сомали и Ливии, хотя в конце 2017 г. правительство Нигера согласилось, что размещенные там беспилотные самолеты США могут быть вооружены [14]. Объем потенциала операции не разглашается. Отдельно региональная военная операция США, известная как операция «Juniper Shield», бюджет которой на 2018 финансовый год составлял \$59 млн., оказывает «поддержку» TSCTP, предположительно, посредством наращивание потенциала в рамках американо-африканского партнерства [15].

Конгресс также уполномочил Министерство обороны США оказывать поддержку «иностранным силам, нерегулярным силам, группам или отдельным лицам, участвующим в поддержке или содействии текущим военные операции» силами специальных операций США по борьбе с терроризмом, хотя Министерство обороны обычно не раскрывают точное местонахождение таких программ.

На слушаньях в Конгрессе в начале 2019 г. тогдашний военных командующий АФРИКОМ США генерал Томас Вальдхаузер заявил, что АФРИКОМ не предоставил «возможности наступательного удара» за пределами Ливии и Сомали, однако пояснил, что любые силы США, сопровождающие местные силы в контртеррористических миссиях, будут иметь «неотъемлемое право на самооборону и коллективную самооборону», если бы они подверглись нападению [16].

В конце 2018 г. Министерство обороны объявило, что сократит военное присутствие США в Западной Африке в свете приоритетов, изложенных в Стратегии национальной безопасности администрации Д.Трампа подчеркивающих соревнование «великих держав».

За последние годы Министерство обороны развернуло военных персонал в Нигер и Камерун, а также построило новый объект ВВС в городе на севере Нигера. Агадес, расположенный на территории военной базы Нигерии, для поддержки 
региональных операций. Начиная с 2013 г. американские военные самолеты были размещены в Ниамее, столице Нигера [17]

Оценить влияние антитеррористических усилий США в Сахеле сложно. В то время как усилия США по обеспечению безопасности и стабилизации возросли за последнее десятилетие, тенденции в области безопасности ухудшились. С другой стороны, трудно оценить, какие худшие сценарии могли бы возникнуть в отсутствие помощи со стороны США.

Хотя некоторые страны, получившие значительную поддержку США и других стран, такие как Нигер и Мавритания, оставались относительно стабильными на фоне региональных потрясений, в других, как Мали, ситуация продолжает ухудшаться.

Большая часть помощи в области безопасности африканским странам, в том числе в Сахеле, осуществляется Госдепартаментом и распределяется через региональные или централизованно управляемые программы, что означает, что она обычно не разбиваются по странам, а отрежется в общих бюджетных документах Конгресса. Конгресс при рассмотрении выделения помощи призвал оказать соответствующую помощь в стабилизации на широкой и гибкой основе, приводя в качестве примеров финансирование ОПМ Госдепартамента и USAID. Большая гибкость может позволить на местах быстро реагировать на меняющиеся обстоятельства и изменять свои подходит при необходимости.

Концепция президента Д. Трампа «Америка прежде всего» вызвала энтузиазм и осуждение среди различных слоев американского населения. Действия Трампа часто были опрометчивыми и хаотичными, тем не менее, по мнению ряда экспертов, некоторые из его внешнеполитических решений значительно лучше, чем утверждают его оппоненты [18] и такая оценка также касается политики США по отношению к странам Африки.

Так, у экспертов и политиков возникает ряд вопросов относительно целесообразности предоставления дальнейшей помощи США странам Африки и борьбы с терроризмом [19]:

- достаточно ли затронуты интересы национальной безопасности США, чтобы требовать новых (или продолжение) инвестиции в финансирование помощи, развертывание вооруженных сил и/или безопасность в рамках партнерских отношений;

- могут ли такие инвестиции эффективно представлять собой превентивные меры по предотвращению будущего угрозы национальной безопасности США;

- подходят ли (и какие) инструменты политики США для решения проблем безопасности, существующие в Сахеле и других регионах Африки;

- должны ли и как Соединенные Штаты работать с авторитарными режимами в целях борьбы с терроризмом и каковы могут быть непредвиденные последствия;

— готовы ли и могут ли другие международные партнеры оказывать положительное влияние на развития событий в регионе, или их вмешательство в проблемы Африки затрагивают интересы США;

- обеспечивают ли департаменты и агентства исполнительной власти достаточное финансирование и могут ли дать оценку результатов, чтобы обеспечить эффективный надзор со стороны Конгресса.

Очевидно, при новой администрации Дж. Байдена США будет более сложно взаимодействовать между помощью в целях развития, дипломатией и внешней политикой. США начинают терять «стратегические» позиции в Африке в пользу таких стран, как Китай, Россия, Индия и других. Однако на данном этапе нет ясности в отношении характера или направления политики Дж.Байдена в отношении Африки. 
Новые подходы должны быть направлены, прежде всего, на привлечение местного потенциала и участников, а не на повышение ожиданий в отношении иностранной помощи, войск и обучения со стороны США.

$$
* * *
$$

1. Peter Duignan and L. H. Gann, The United States and Africa: A History Cambridge: Cambridge University Press. 1984.

2. The Spanish American War. URL: https://history.state.gov/milestones/1866-1898/spanish-american-war (дата обращения 15.01.2021).

3. The Atlantic Charter. URL: http://www.history.com/topics/world-war-ii/atlantic-charter (дата обращения 18.01.2021).

4. Text of Atlantic Charter. URL: https://www.history.com/topics/world-war-ii/atlantic-charter (дата обращения 23.01.2021).

5. Lions on the move II: Realizing the Potential of Africa's Economies, 2016. McKinsey Global Institute.URL: https://www.mckinsey.com/featured-insights/middle-east-and-africa/lions-on-the-moverealizing-the-potential-of-africas-economies (дата обращения 24.01.2021).

6. Douglas I. Understanding Trump's Trade War // Foreign Policy. Winter 2019. URL: https://foreignpolicy.com/gt-essay/understanding-trumps-trade-war-china-trans-pacific-nato/ (дата обращения 19.01.2021).

7. Renshon S. A., Suedfeld P (Ed).The Trump Doctrine and the Emerging International System. Palgrave Macmillan. 2020. 432 p.

8. US Secretary of Commerce Wilbur Ross, announces $\$ 1$ billion in deals during Africa mission. US Department of Commerce. 06 July 2018. URL: https://agoa.info/news/article/15465-us-secretary-ofcommerce-wilbur-ross. (дата обращения 16.01.2021).

9. Statement by Acting Assistant Secretary of State for Africa Daniel Yamamoto, "Political Crisis in the Democratic Republic of the Congo". US House of Representatives, Foreign Affairs Subcommittee on Africa, Hearing, November 9, 2017.

10. Remarks by Assistant Secretary of State Tibor Nagy, https://www.state.gov/baker-institute-for-publicpolicy-at-rice-university (дата обращения 22.01.2021).

11. Overview . US International Development Finance. URL: Corporation URL: https://www.dfc.gov/whowe-are/overview (дата обращения 11.01.2021).

12. Deputy Secretary of State John J. Sullivan, "Counterterrorism Efforts in Africa". US House of Representatives, Committee on Foreign Affairs, Hearing, December 7, 2017.

13. Center for Strategic and International Studies, "U.S. Economic Engagement in Africa: Making Prosper Africa a Reality" (Washington, DC, April 2019).

14. New York Times, "Niger Approves Armed U.S. Drone Flights, Expanding Pentagon's Role in Africa," November 30, 2017.

15. Office of the Secretary of Defense, FY2020 Justification for Component Contingency Operations, the Overseas Contingency Operation Transfer Fund (OCOTF), May 2019.

16. Hearing before the Senate Armed Services Committee, U.S. Africa Command and Southern Command, February 7, 2019.

17. Force Times, "Armed Drones to Fly Out of Niger Air Base Now Operational After Delayed Completion," November 1, 2019.

18. Conley R.S. Donald Trump and American Populism: New Perspectives on the American Presidency.Published by: Edinburgh University Press. 2020. 372 p.

19. U.S. Counterterrorism Priorities and Challenges in Africa. Congressional Research Service TE10044 December 16, $2019 \quad$ URL: https://crsreports.congress.gov/search/\#/2?termsToSearch=africa\&orderBy=Relevance (дата обращения 25.01.2021).

\section{Ali Abdirahman Ahmed Extremism as a threat to the national security of Somalia}

